\title{
Towards a Better Smoke Alarm Signal - an Evidence Based Approach
}

\author{
DOROTHY BRUCK and IAN THOMAS \\ School of Psychology and Centre for Environmental Safety and Risk Engineering (CESARE) \\ Victoria University \\ PO Box 14428 \\ Melbourne 8001 \\ Australia
}

\begin{abstract}
This paper focuses on experimental findings on the waking effectiveness of different auditory signals in children, deep sleeping young adults, older adults, the hard of hearing and the alcohol impaired. Wherever possible, data is graphically presented in terms of the percentage sleeping through different sounds at 75 dBA. It includes previously unpublished data comparing the waking effectiveness of various signals in young adults who were either sober or moderately impaired with alcohol. A summary of the evidence concerning the best and worst signal shows that the $520 \mathrm{~Hz}$ square wave signal is at least 4 to 12 times more effective than the current high pitched signal in the populations tested. Research supporting lower frequency signals and mixed frequency signals as being the best alarms for people when awake is also discussed. It is argued that the $520 \mathrm{~Hz}$ square wave signal, which has been tested now in six different experimental studies, has a sufficient evidence base to warrant the recommendation for its widespread introduction as a new smoke alarm signal for the whole population. Not improving the alarm signal is likely to result in fatalities and injuries that may have been avoidable.
\end{abstract}

KEYWORDS: alarms, smoke detectors, sleep, human behaviour in fire, auditory arousal, response patterns

\section{INTRODUCTION}

The paper consists of four parts. Part 1 is a review of the literature evaluating the effectiveness of a variety of smoke alarm sounds in waking sleepers and begins with a short overview about smoke alarm signal standards. The review of the experimental research is divided according to whether sleepers were presented with sounds of a constant volume, or sounds increasing in a stepped volume procedure. The data is graphically presented in a new form which readily allows comparisons across studies, with figures showing the percentage sleeping through different sounds at set volumes, usually $75 \mathrm{dBA}$. Part 2 presents previously unpublished data of a recent study which compared the waking effectiveness of various sounds in young adults who were either sober or moderately impaired with alcohol. Part 3 summarizes the experimental evidence and compares the waking effectiveness rates of the best and worst alarm sound in the populations tested. Part 4 examines various acoustical issues, including research showing that lower frequency sounds and mixed frequency sounds are the best alarms for people when awake, as well as when asleep.

\section{REVIEW OF THE LITERATURE ON WAKING TO ALARMS}

When residential smoke alarms were first developed and widely distributed in the 1970s the focus was on the technology to detect smoke and/or heat and little attention was paid to the nature of the signal. Assurances about the ability of the signal to awaken people provided in the appendix to the National Fire Protection Agency 1975 Code were not supported by the published auditory arousal threshold data available at the time [1,2], with one author noting in 1978 that people may 'in fact, require over $100 \mathrm{~dB}$ ' [2, pg 106]. The standards in some countries specify a minimum alarm volume at the pillow, such as 75 $\mathrm{dBA}[3,4]$. A smoke alarm that meets the requirement to emit $85 \mathrm{dBA}$ at 10 feet [5] is likely to achieve 75 $\mathrm{dBA}$ at the pillow only if it is within the bedroom. Hallway placement of an alarm, which is widespread in many countries, can be expected to result in a reduction of $12 \mathrm{dBA}$ if the door is open and 15-20 dBA if the door is closed [6]. Any additional complexity of the sound path, such as a corners or a different level of the house, will lead to further reductions [7]. Single station smoke alarms in bedrooms compared to hallways will have more chance of waking sleeping occupants but may not promptly detect fires burning elsewhere 
in the home. Interconnected alarms will overcome this problem but their installation is not common around the world.

In various Western countries fire alarms are now being sold which emit the Temporal-Three (T-3) pattern. The International Standard [8] defines the T-3 signal and this was adopted by the US National Fire Protection Agency [3], Underwriters Laboratories [5] and the Building Code of Canada in the mid 1990s as the required fire alarm signal in building fire warning installations. The Australian Standard adopted the T3 as the required fire occupant warning signal in 2004 [4] but many smoke alarms currently sold do not use the T-3 pattern. The T-3 sets out a specific temporal pattern of three 0.5 second on and off pulses, with a 1.5 second pause between each set of three pulses. The International Standard does not limit the fire alarm signal to any one sound, so signals of different frequencies and acoustic characteristics can be used within the T-3 specification. The aim is that people will recognise the specific timing pattern as the signal to evacuate immediately (although in our experience this is not the case).

\section{Research with adults and the standard alarm at set volumes}

The first published study that tested whether adults would awaken to the standard high pitched smoke alarm signal (3000-5000 Hz depending on brand) was conducted in 1981 [9]. Time of night varied across participants and sleep stage was not controlled. All of the 10 young adults (18-29 yrs) awoke within 21 seconds to the $55 \mathrm{dBA}$ signal (pillow volume) and within 16 seconds to the $70 \mathrm{dBA}$ signal. Several years later 12 young adults were tested 2, 4 and 6 hours after lights out and it was found that only $50 \%$ awoke to the $54 \mathrm{dBA}$ pillow volume, while $100 \%$ awoke to $78 \mathrm{dBA}$ [10]. The first alarm study that controlled for sleep stage (stages 2, REM and 4) at the time of signal presentation [11] tested eight young adults. While $80 \%$ awoke reliably to the $60 \mathrm{dBA}$ signal, those who slept through self reported lack of sleep the night before due to exam preparation. In a further study of adults, this time in their own homes with no control of sleep stages [12], it was found that $100 \%$ of the sixteen $30-59$ year old adults awoke to a $60 \mathrm{dBA}$ signal activated at $1 \mathrm{am}$ or $4.30 \mathrm{am}$. More recently 32 people with established normal hearing were tested [13] across the sleep stages of stage 4, 2 and REM. A high frequency smoke alarm was presented for two minutes at "less than $75 \mathrm{dBA}$ " and it was found that $96 \%$ of participants awoke.

The overall pattern of these results is that the presentation of the standard high pitched alarm to unimpaired adults will typically result in quite quick awakening whether the stage of sleep is controlled or not. The demonstrated caveat on this conclusion is where a young adult had prior sleep deprivation [11].

\section{Research with children and alarm signals at a set volume}

The first indication that children may have difficulty waking to the standard alarm was a study by Bruck [12] which found that $94 \%$ of children aged 6-15 years did not awake reliably (i.e. two out of two alarm presentations) to a standard alarm installed in their hallway and received at the pillow at $60 \mathrm{dBA}$. Subsequent studies $[14,15]$ tested different signals at $89 \mathrm{dBA}$ at the pillow and found results as shown in Fig. 1. The signals were activated at set times during the night (1am and 4 am) and sleep stage was not monitored or controlled. The number of tests for each signal varied from 20 to 28 and different children typically received different signals (except that the two voice alarms were tested on the same children). It can be seen that children slept through $43 \%$ of the presentations of the current high pitched alarm and that this signal performed much more poorly than the three alternative signals presented, where less than $4 \%$ slept through. The $520 \mathrm{~Hz}$ square wave mentioned in Fig. 1 (and subsequent figures) has been variously described by Bruck and colleagues as the "low pitched T-3" or "mixed T-3". Both descriptions refer to a signal that was originally a Simplex 1996, 4100 Fire Alarm Audio Demonstration CD from Canada and was subsequently identified as a $520 \mathrm{~Hz}$ square wave (described below in the final part of this paper). 


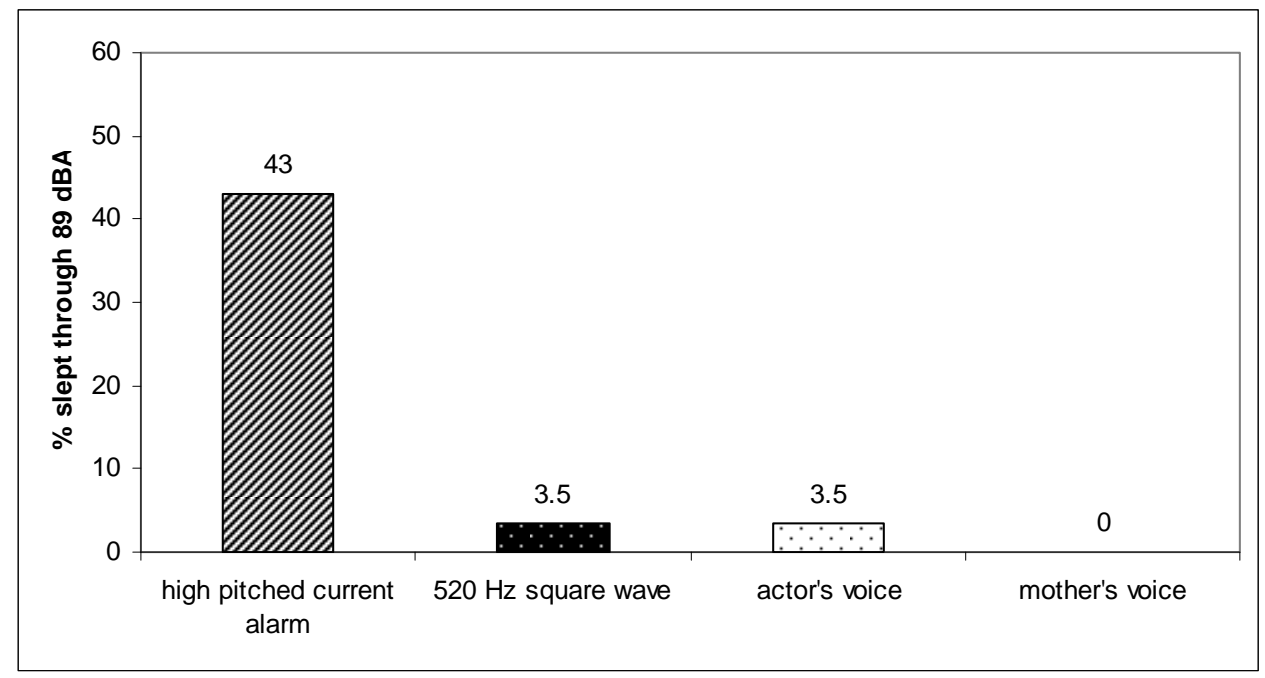

Fig. 1. Percentage of children aged 6 -10 years who slept through different 89 dBA signals [15].

In a subsequent USA study [16] using a volume of $100 \mathrm{dBA}$ the high pitched alarm was compared to a mother's voice alarm in twenty four 6-10 year olds, controlling for sleep stage (stage 4). It was found that in $96 \%$ of cases the child awoke to a mother's voice alarm while only $58 \%$ of presentations of the high pitched alarm resulted in awakenings.

\section{Research with signals presented in increasing stepped volumes}

One of the problems with studies presenting alarm signals at a single volume is that they limit the amount of data yielded. In effect there is only one data point per signal tested - either the person awoke or did not awake. Further, the single presentation of a signal at a set volume does not allow very sensitive comparisons across different signals and gives limited indication about what volume of a certain signal may be effective in waking the sleeper under the experimental conditions. It is assumed that waking to one signal (A) at a lower volume than another signal (B) indicates the increased waking effectiveness of A. In the research by Bruck and colleagues on alarms and adults after 2002 a procedure where different volumes of a signal were presented in consistent, ascending steps was used. In these studies a continuous signal was emitted from a bedside speaker for 30 seconds, starting at 35 or $55 \mathrm{dBA}$ and increasing in specified volume increments to a maximum of $95 \mathrm{dBA}$ (with the $95 \mathrm{dBA}$ continuing for a further three minutes). Measured responses were both a waking EEG pattern and the pressing of a bedside button. The signals were presented during a specified stage of sleep (typically the deepest stage, stage 4). In all the studies presented below all the participants within each study normally received all the various signals. This repeated measures design adds sensitivity to the data as each person essentially acts as their own control. Given the large individual differences between arousal thresholds it is the preferred design for such studies.

In the following sections the research data will be graphed in a new form. Each signal will be presented graphically in terms of what percentage of participants in the study slept through the signal presentations at volumes between 35 and $75 \mathrm{dBA}$ (inclusive) at the pillow. In Figs. 2 and 3 each volume was presented for 30 seconds in $5 \mathrm{dBA}$ increments from $35 \mathrm{dBA}$ with no silences between steps. However, in the studies shown in Figs. 4-6 30 second silences were inserted between each volume step of $10 \mathrm{dBA}$, beginning at 55 $\mathrm{dBA}$. For this reason, and because of differences in the participants used in the different studies, comparisons should be confined to responsiveness to different signals within each study, not across different studies. Moreover, caution should be exercised in extrapolating the decibel levels found in the experimental setting to those in a field setting (i.e. residences). This has been discussed in detail elsewhere $[17,18]$ The reasons for such caution relate to the highly selected populations used and the methodology where signals were tested during the deepest stage of sleep, sometimes not presented from silence, and presented to participants who were expecting to be awoken with a signal (i.e. primed to respond). Although the differential effect of these various factors is uncertain, it seems most likely that the data 
presented here are underestimations of the number likely to sleep through a $75 \mathrm{dBA}$ signal presented in their homes in a typical scenario of the smoke alarm being activated during the sleeping period. The level of $75 \mathrm{dBA}$ was chosen as it is often recommended as the minimal volume at the pillow for bedrooms. Note that all beeping signals (i.e. non-voice) are in a T-3 pattern in all studies presented below.

The exact spectral specifications of the high pitched alarm signal used in the described studies changed with time. But in all cases the dominant frequency was above $3000 \mathrm{~Hz}$. In the early studies, including those with children [14] and the deep sleeping young adults discussed below [19], the alarm was a continuously sounding beeping noise from $3,500 \mathrm{~Hz}$ to over $5,000 \mathrm{~Hz}$ [spectral analysis in 19]. In all the studies after 2004 by Bruck and colleagues presented here $[17,18,20,22]$ a T-3 alarm with a single dominant frequency of $3100 \mathrm{~Hz}$ was used.

\section{Self-reported deep sleeping young adults}

A study published in 2004 [19] recruited young adults aged between 18 and 26 years who reported themselves as being particularly deep sleepers and tested the waking effectiveness of different signals in the stepped volume procedure described above. Figure 2 shows the percentage of sober young adults $(n=14)$ who awoke from deep sleep (stage 4) to different signals at the benchmark of $75 \mathrm{dBA}$. Statistical analyses revealed that the high pitched current alarm was significantly less effective at waking the young adults than the other two signals and that there was no significant difference between the efficacy of the $520 \mathrm{~Hz}$ square wave and the female actor's voice. Only one participant slept through the loudest and longest presentation of an alarm ( 3.5 minutes at $95 \mathrm{dBA})$ and this was for the high pitched alarm.

The same study also tested the participants under conditions of alcohol impairment and found the waking effectiveness of the different signals to be (in order of increasing effectiveness) the high pitched current alarm, actor's voice and $520 \mathrm{~Hz}$ square wave. However, this data is not reproduced here as the more recent, larger study examining waking responsiveness to different signals under conditions of alcohol impairment will be presented instead (see below).

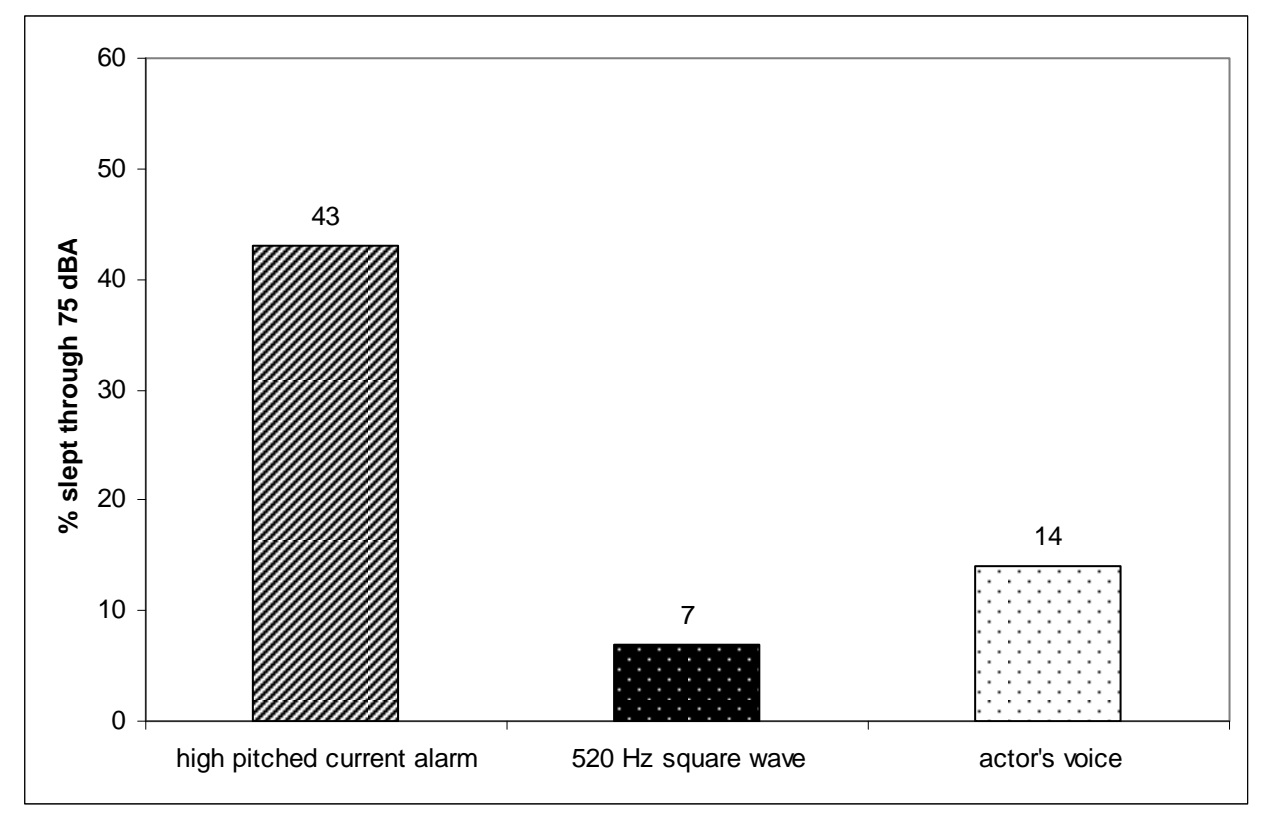

Fig. 2. Percentage of young adults (self-reported deep sleepers) $(n=14)$ who slept through signals presented at $75 \mathrm{dBA}[19]$.

\section{Older adults}

Forty two sleeping adults aged 65-83 years who had been carefully screened to be free of hearing problems, medication affecting sleep and were physically and cognitively capable were tested during deep sleep (stage 3 ) with a variety of alarms $[17,18]$. The results showed that the volume needed to wake up to the 
high pitched alarm was significantly higher than that needed with the $520 \mathrm{~Hz}$ square wave. The most important findings were that the older adults awoke to a lower volume for the $520 \mathrm{~Hz}$ square wave signal (median $=45 \mathrm{dBA}$ ) compared to the other three signals tested (male actor's voice, $500 \mathrm{~Hz}$ pure tone and high pitched signal). Indeed, the current high pitched alarm needed the highest volume (median $=65 \mathrm{dBA}$ ) to produce awakenings compared to the other signals. Figure 3 shows the differences in signal performance at $75 \mathrm{dBA}$ for these older adults. The largest differences between the signals occurred at less than $65 \mathrm{dBA}[18]$.

Consideration of the numbers of older adults who slept through the prolonged (3.5 minutes) presentation of the $95 \mathrm{dBA}$ level signals reveals that all participants awoke to the $520 \mathrm{~Hz}$ square wave, while one participant did not wake to the $500 \mathrm{~Hz}$ pure tone $(2.3 \%)$ and one did not wake to the current high pitched alarm $(2.3 \%)$. Interestingly three $(7.5 \%)$ of this older adult group did not awaken at all to the actor's voice (3.5 minutes at $95 \mathrm{dBA}$ ). On closer inspection of the raw data it was determined that two of these people were from a non-English speaking background (Arabic) and had participated in the study with the help of a translator. They had not slept through any other signal presented.

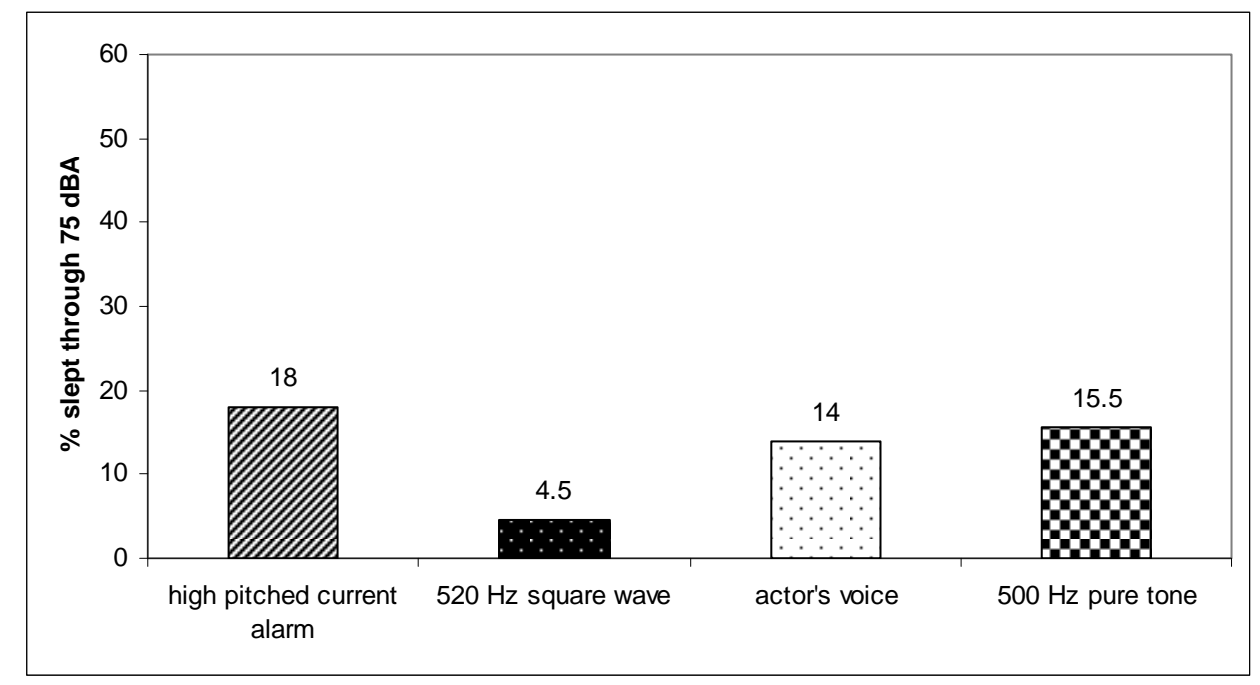

Fig. 3. Percentage of older adults aged 65 to 83 years $(n=42)$ who slept through signals presented at 75 dBA $[17,18]$.

\section{Adults who are hard of hearing}

The 38 adults tested in this study [20] had an average hearing loss of 25-70 dBA in both ears (i.e. mild to moderately severely impaired, but not deaf). The first phase involved identifying which signals had the lowest hearing thresholds when awake as these would be included among the auditory signals tested when asleep. Two square wave signals (with a fundamental frequency of $400 \mathrm{~Hz}$ or $520 \mathrm{~Hz}$ ) had the lowest auditory response thresholds (with the latter having the lowest of all those tested, although the differences were minor). The other signals included low frequency pure tones, whoops in the range $400-800 \mathrm{~Hz}$ and 400-1600 Hz, white noise and a $3100 \mathrm{~Hz}$ pure tone. The latter was a recording from a standard high pitched smoke alarm and the auditory threshold (when awake) for this signal was found to be significantly ( $\mathrm{p} \leq .01$ ) higher than the threshold for the $400 \mathrm{~Hz}$ and $520 \mathrm{~Hz}$ square waves.

Testing when asleep showed that the two square waves were significantly more effective at waking this population than the high pitched current alarm signal (see Fig. 4). Consideration of the number who slept through the prolonged presentation of a $95 \mathrm{dBA}$ signal (3.5 minutes) found that $15.6 \%$ of the participants slept through such a presentation of the current alarm, while none slept through the $520 \mathrm{~Hz}$ square wave. 


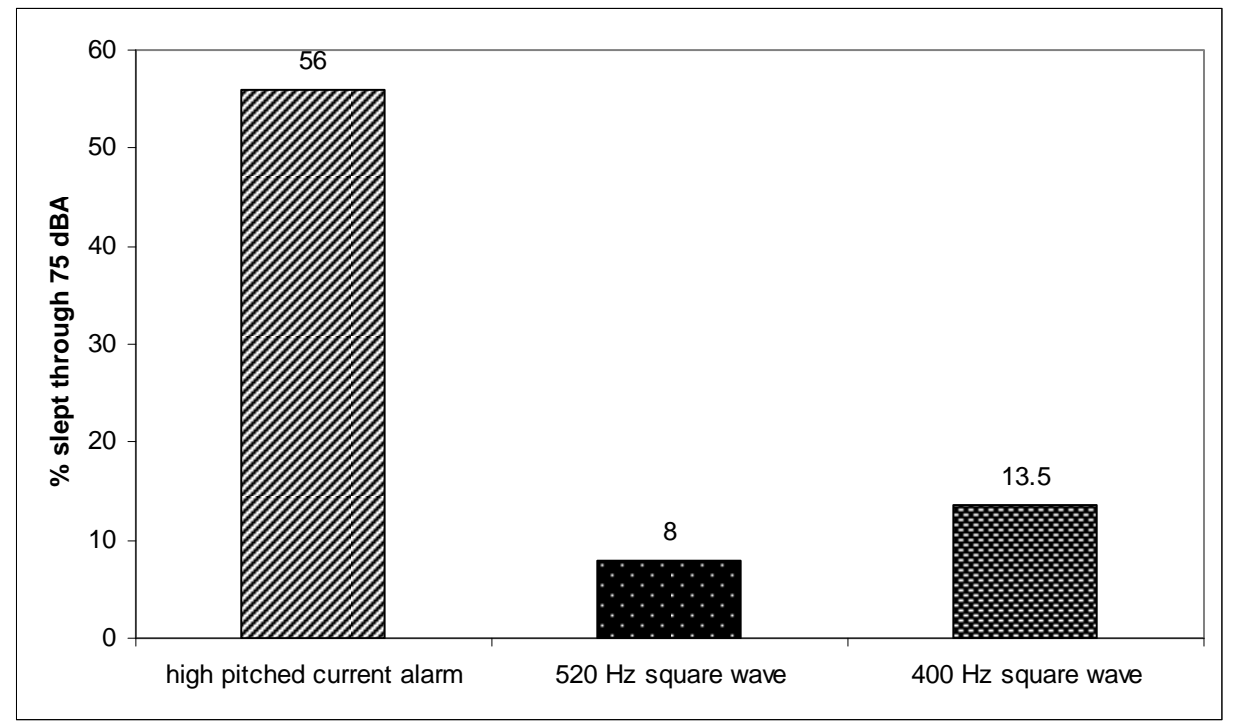

Fig. 4. Percentage of adults with mild to moderately severe hearing loss $(n=38)$ who slept through signals presented at $75 \mathrm{dBA}[17,18]$.

\section{RECENT RESEARCH ON SOBER AND ALCOHOL IMPAIRED YOUNG ADULTS}

Alcohol impairment has been found to greatly increase the probability of death from fire and has been described as the single most significant risk factor for fire fatality [21]. Consequently a comparison of the waking effectiveness of different signals for such a population was of special interest. In this study [22] 32 participants aged from 18 to 27 years, were who were self reported normal sleepers, drank vodka and orange to achieve a Blood Alcohol Content (BAC) of 0.05 prior to going to sleep. For a variety of reasons not all participants received each signal and in Fig. 5 below 27 or 28 participants received the two square waves and $500 \mathrm{~Hz}$ pure tone, but only 13 received the high pitched alarm signal. It was found that with 0.05 $\mathrm{BAC}$ the waking effectiveness of the high pitched sound was significantly worse than the square wave sounds $(\mathrm{p}=.03$ ). While no one slept through the $75 \mathrm{dBA} 520 \mathrm{~Hz}$ square wave signal, almost $40 \%$ slept through the high pitched signal at $75 \mathrm{dBA}$.

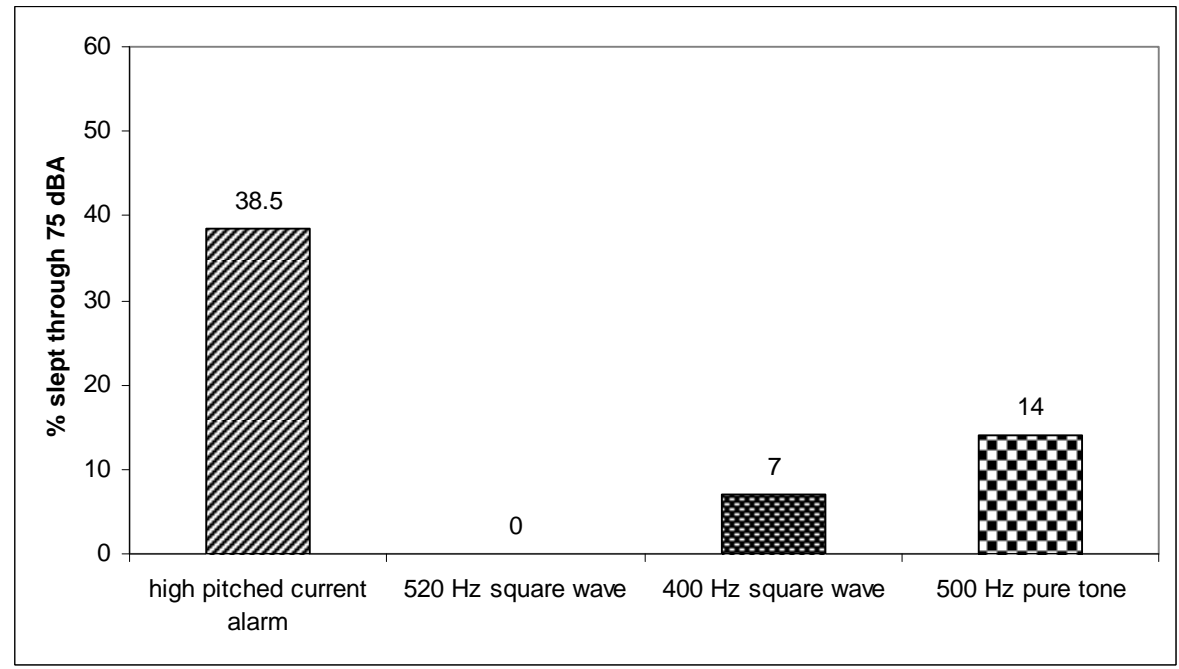

Fig. 5. Percentage of young adults with 0.05 Blood Alcohol Content who slept through signals presented at $75 \mathrm{dBA}[22]$.

Twenty four of the participants in the $0.05 \mathrm{BAC}$ data collection above also volunteered to completed a subsequent night with no alcohol ingestion. On that night three auditory signals were presented during 
stage 4 sleep, with the signal order counterbalanced across subjects. (The same participants had received four auditory and two non-auditory signals across two nights in the $0.05 \mathrm{BAC}$ condition.) The percentages of sober young adults who slept through $75 \mathrm{dBA}$ signals are shown in Fig. 6.

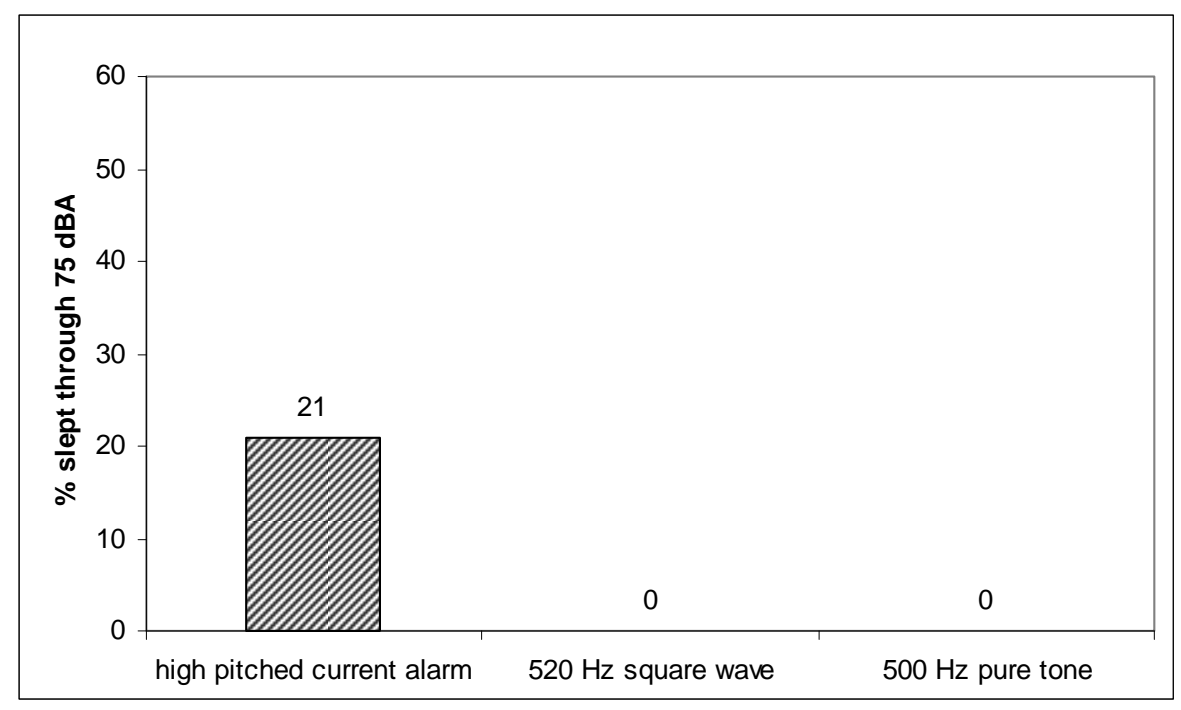

Fig. 6. Percentage of sober young adults who slept through signals presented at $75 \mathrm{dBA}(\mathrm{n}=24)$.

This new data shows that no participants slept through the $75 \mathrm{dBA}$ signals for the $520 \mathrm{~Hz}$ square wave or the $500 \mathrm{~Hz}$ pure tone. In contrast, about one in five sober young adults slept through the $75 \mathrm{dBA}$ high pitched alarm. No participant slept through the highest volume presentation of any of the signals ( $95 \mathrm{dBA}$ for 3.5 minutes).

The results above for the two lower frequency signals on this may be a result of a floor effect. Thus further analyses were conducted based on dependent variables that allow for more sensitive comparisons, such as the time required to make a behavioural response (pressing a bedside button three times). (Note that this is measured from the initial onset of the $35 \mathrm{dBA}$ signal and includes the various $10 \mathrm{dBA}$ steps and 30 second silences. It is not a measure of reaction speed to a signal.) Table 1 summarises the behavioural response time (in seconds) for each signal.

Table 1. Descriptive statistics for behavioural response time (in seconds) across the different signals in sober young adults.

\begin{tabular}{l|lll}
\hline & $\begin{array}{l}\text { Mean } \\
\text { (standard deviation) }\end{array}$ & Median & Range \\
\hline $520 \mathrm{~Hz}$ square wave & $30.4(38.5)$ & 13.5 & $6-141$ \\
$500 \mathrm{~Hz}$ pure tone & $51.2(46.1)$ & 21.5 & $5-156$ \\
$3100 \mathrm{~Hz}$ pure tone & $108.0(63.3)$ & 85.5 & $11-246$ \\
\hline
\end{tabular}

It can be seen that the two lower frequency signals produced faster behavioural response times than the $3100 \mathrm{~Hz}$ signal. The Friedman test comparing the three signals found a significant difference $\left(X^{2}=22.4\right.$, $\mathrm{df}=2, \mathrm{p}=.000$ ). Post hoc Wilcoxon signed rank tests were then performed between pairs of variables to uncover where the real differences lay and showed significant differences between the $520 \mathrm{~Hz}$ square wave and the $500 \mathrm{~Hz}$ pure tone $(\mathrm{Z}=-2.6, \mathrm{p}=.008)$ and between the $500 \mathrm{~Hz}$ pure tone and the $3100 \mathrm{~Hz}$ pure tone $(\mathrm{Z}=-3.5, \mathrm{p}=.000)$. Thus the $520 \mathrm{~Hz}$ square wave sound was significantly better than the other two signals using behavioural response time as the measure. 


\section{SUMMARY OF DIFFERENCES IN WAKING EFFECTIVENESS OF TWO KEY SIGNALS}

The data presented above shows that the current high pitched smoke alarm was consistently the worst at waking people. Examination of Figs. 1-6 also shows that in the majority of cases the best performing signal was the $520 \mathrm{~Hz}$ square wave. The only exception to this is the study with children (Fig. 1), where alarms of the mother's voice performed marginally better. Subsequent research involving adults over 65 years (Fig. 3 ) indicated that a voice alarm performed comparatively poorly with this population, and in particular, that alarms in the English language may not effective for waking non-English speakers. For this reason the testing of voice alarms was not pursued in subsequent studies.

Table 2 presents a summary of the comparison across the different studies and populations tested. The ratios calculated show that the likelihood of sleeping through a $75 \mathrm{dBA}$ high pitched alarm was at least between 4 and 12 times the likelihood of sleeping through the $520 \mathrm{~Hz}$ square wave. The philosophy behind the campaign for smoke alarms is that a smoke alarm sounding during the sleeping period will save lives in the event of a fire because it will wake up people. Thus it follows that the experimental data suggests that a child, for example, would be 12 times less likely to wake up to a high pitched smoke alarm signal than one sounding a $520 \mathrm{~Hz}$ square wave signal.

Table 2. Summary of studies discussed above, plus the ratio of those who slept through the high pitched alarm versus those who slept through the $520 \mathrm{~Hz}$ square wave (at the specified volume).

\begin{tabular}{|c|c|c|c|c|c|c|}
\hline \multirow[t]{2}{*}{ Participants } & \multirow{2}{*}{$\begin{array}{l}\text { Reference } \\
\text { Number }\end{array}$} & \multirow{2}{*}{$\begin{array}{l}\text { Alarm } \\
\text { volume } \\
(d B A)\end{array}$} & \multirow{2}{*}{$\begin{array}{l}\text { Figure } \\
\text { showing } \\
\text { results }\end{array}$} & \multicolumn{2}{|l|}{$\%$ slept through } & \multirow[t]{2}{*}{ Ratio } \\
\hline & & & & $\begin{array}{l}\text { high pitched } \\
\text { current alarm }\end{array}$ & $\begin{array}{l}520 \mathrm{~Hz} \text { square } \\
\text { wave }\end{array}$ & \\
\hline children aged 6-10 yrs & 14 & 89 & 1 & $43 \%$ & $3.5 \%$ & $12: 1$ \\
\hline $\begin{array}{l}\text { deep sleeping young } \\
\text { adults }\end{array}$ & 19 & 75 & 2 & $43 \%$ & $7 \%$ & $6: 1$ \\
\hline $\begin{array}{l}\text { older adults aged }>65 \\
\text { yrs }\end{array}$ & 17,18 & 75 & 3 & $18 \%$ & $4.5 \%$ & $4: 1$ \\
\hline hard of hearing adults & 20 & 75 & 4 & $56 \%$ & $8 \%$ & $7: 1$ \\
\hline 0.05 BAC young adults & 22 & 75 & 5 & $38.5 \%$ & 0 & $\mathrm{n} / \mathrm{a}$ \\
\hline sober young adults & new data & 75 & 6 & $31 \%$ & 0 & $\mathrm{n} / \mathrm{a}$ \\
\hline
\end{tabular}

\section{ACOUSTICAL CONSIDERATIONS}

The $520 \mathrm{~Hz}$ square wave has a fundamental frequency at $520 \mathrm{~Hz}$ and then subsequent peaks at the $3^{\text {rd }}, 5^{\text {th }}$, $7^{\text {th }}$ etc harmonics (see Fig. 7). It is not immediately obvious why square wave signals should be the most effective signal tested so far for waking people up. Square waves have been described as having a dissonant sound and the subjective "fullness" of the sound may give an impression of being louder (although this is not reflected in sound meter levels). It may be because human responsiveness to sounds 
while asleep is best when the signal includes a range of frequencies. If this were the case it would be expected that a voice alarm would be equally effective. Yet responsiveness to a voice alarm has yielded inconsistent results and importantly, the research using older adults $[17,18]$ found the voice signal to be significantly less effective than the $520 \mathrm{~Hz}$ square wave. Problems of non-awakening, even at $95 \mathrm{dBA}$ for over three minutes, were found for non-English speakers with English language voice alarms.

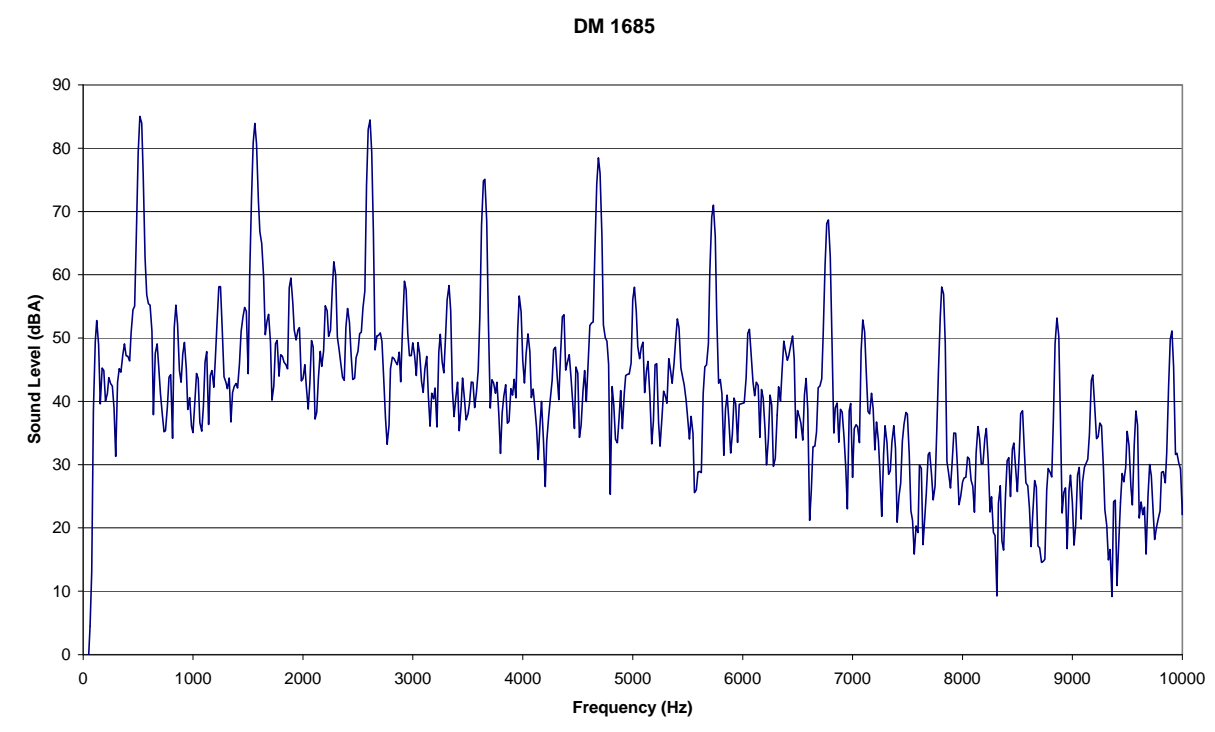

Fig. 7. Spectral analysis of the $85 \mathrm{dBA} 520 \mathrm{~Hz}$ square wave in the testing bedroom [20].

Various researchers have considered the nature of the most effective alarms and/or ringer tones for alerting people who are awake. One author [23] notes

Contrary to the general conception of pitch perception, we do not hear a separate pitch for each peak in the spectrum of a sound. Rather, the auditory system takes the information from temporally related components and maps them back onto one perception, namely a pitch corresponding to the fundamental of the harmonic series implied by the related components. This ....enables us to design warnings that are highly resistant to masking by spurious noise sources. [pg. 488]

The warning sound advocated for the cockpit of a Boeing 747 is one with a series of harmonics that are at least $15 \mathrm{~dB}$ above the auditory threshold, which will vary depending on background noise. A sound with four or more components in the appropriate level range is advocated as it is much less likely to be masked [23].

In testing the audibility of various ringer tones in both $20-30$ year olds and 70-95 year olds it was found that the "electronic bell" had the lower audibility thresholds for both age groups [24]. The advantage of this ringer was attributed to its prominent energy peaks between 1000 and $1600 \mathrm{~Hz}$, with the less effective alternatives having more high frequency content. Their findings were consistent with an earlier report by Hunt [25] who used the theory of critical band masking to predict the most effective telephone ringer tone. Hunt concluded that at least two spectral components between 500 and $4500 \mathrm{~Hz}$ were desirable to aid detection of a ringer above background noises. Moreover, Hunt cited an earlier research report by Archbold and colleagues (1967) that concluded that at least one of these components should be less than $1000 \mathrm{~Hz}$. This conclusion would help those with age related hearing loss who generally have better hearing below $1000 \mathrm{~Hz}$. These recommendations are all consistent with the spectral profiles of the square waves used in the sleep studies.

One question that arises is whether the single best square wave is actually one with a fundamental frequency of $520 \mathrm{~Hz}$ or whether one that has a higher fundamental frequency may be as effective or better. This question has importance given that it is technically more difficult to produce a high volume lower frequency sound than a sound with a higher frequency at the same decibel level. The key issues appear to be the power and speaker requirements, especially in single station, battery powered smoke alarms. 
However, for hard of hearing people a fundamental frequency of $520 \mathrm{~Hz}$ or thereabouts seems likely to be the most effective. Evidence supporting this is (i) the finding that the mean hearing threshold for a $500 \mathrm{~Hz}$ tone presented during the audiological screening test of participants for the hard of hearing study [20](when awake) was lower than for $1000 \mathrm{~Hz}, 2000 \mathrm{~Hz}$ and $4000 \mathrm{~Hz}$ (with the latter having the highest mean) ; (ii) testing of the auditory thresholds for the various signals that were presented when asleep showed that, when awake, the hard of hearing population had the lowest threshold to the $520 \mathrm{~Hz}$ square wave compared to all other pure and mixed sounds presented [20] and, (iii) the hearing thresholds in a population-based study of 3,753 people aged 48-92 years [26] found the average thresholds for the $500 \mathrm{~Hz}$ sound were lower than for $250 \mathrm{~Hz}, 1000 \mathrm{~Hz}, 2000 \mathrm{~Hz}, 3000 \mathrm{~Hz}$ and higher frequencies. Overall, all the findings are consistent with the idea that the most detectable signal when awake may also be the most alerting when asleep.

A study nearing completion by our team ( $\mathrm{n}=30$ young adults tested in stage 4 sleep) has compared square waves at various fundamental frequencies $(400,520,800,1600 \mathrm{~Hz})$ with other signals consisting of whooping sounds ( $0.5 \mathrm{sec}$ whoop between $400-1600 \mathrm{~Hz}$ and one between $400-800 \mathrm{~Hz}$ ), white noise and a set of pure tones $(400,800$ and $1600 \mathrm{~Hz})$. Preliminary results show that square waves performed significantly better than the alternatives tested, and among the square waves, the $520 \mathrm{~Hz}$ signal had the lowest arousal thresholds (although the differences between the square waves are minor).

The high pitched current alarm has now been consistently shown to be the least effective signal tested for waking up children, young sober adults, young alcohol impaired adults, older adults and the hard of hearing. Its other drawbacks include the fact the high frequency hearing loss is a normal part of aging, with decrements in thresholds for sounds above $2000 \mathrm{~Hz}$ beginning to be clearly evident in populations over 40 years, especially males $[24,26]$. This would be one disadvantage of simply increasing the volume of the current high pitched signal to say, $95 \mathrm{dBA}$ at the pillow. The study of hard of hearing adults reported above [20] found that $16 \%$ still slept through such a high volume high pitched signal while none slept through the $95 \mathrm{dBA} 520 \mathrm{~Hz}$ square wave. A further disadvantage is that high frequencies (e.g. above $2000 \mathrm{~Hz}$ ) are more easily reduced by doors and walls than are frequencies at or below $500 \mathrm{~Hz}$ [27].

\section{CONCLUSION}

The high pitched alarm is subjectively piercing and hard to ignore, and people understandably assumed it would do the job. However, even in the 1970s it was reported that an examination of the arousal threshold literature gave cause for doubt [2]. The evidence now unequivocally exists that we can do better. Indeed, the research published over the last decade and presented here suggests that the $520 \mathrm{~Hz}$ square wave signal is at least 4 to 12 times more effective than the current signal. Thus, for populations at risk, not improving the signal may result in fatalities and injuries that were avoidable. Given such evidence, the relevant standards committees should make specific recommendations about the frequency of the alarm signal to be emitted by smoke detectors and the $520 \mathrm{~Hz}$ square wave should be adopted as the mandated signal for all populations.

Mandating the signal only for specific at-risk population groups makes no sense given that we all age (and thus have declining high frequency hearing), children may sleep in different beds within a household, most people consume some alcohol some time, millions of people take sleeping tablets (designed to reduce responsiveness to stimuli during sleep) every night and room occupancies across the population frequently change.

\section{ACKNOWLEDGEMENTS}

The financial support provided by the Fire Protection Research Foundation [18, 20, 22], Onesteel [19] and the Australian Research Council $[14,19]$ is gratefully acknowledged. Special thanks to Michelle Ball and Michelle Barnett.

\section{REFERENCES}

[1] Bonnet, M. Performance during sleep. in Biological Rhythms, Sleep and Performance. WB.Webb (Ed.) J. Wiley \& Sons, 1982, pp. 205-237.

[2] Berry, C. H. (1978). Will your smoke detector wake you? Fire Journal, July, 105-108.

[3] NFPA 72 (2002). National Fire Alarm Code, National Fire Protection Agency, Quincy, MA. 
[4] Australian Standard (AS) 1670.4 (2004). Fire detection, warning, control and intercom systemsSystem design, installation and commissioning. Part 4: Sound systems and intercom systems for emergency purposes. Sydney: Standards Australia

[5] Underwriters Laboratories (1976). Single and multiple station smoke alarms (217), Underwriters Laboratories, Northbrook, IL.

[6] Robinson, D. A. (1986). Sound transmission loss from corridors to rooms: implications for locating fire alarm sounders. Fire Technology, 22(2), 122-135. doi:10.1007/BF01047421

[7] Lee, A. (2005). The audibility of smoke alarms in residential homes. CPSC-ES-0503. US Consumer Product Safety Commission, Washington D.C. 20207-0001. February 2005.

[8] ISO 8201(1987). Acoustics - audible emergency evacuation signal. International Organisation for Standardisation (ISO), Geneva, Switzerland.

[9] Nober, E. H., Peirce, H. \& Well, A. (1981). Waking effectiveness of household smoke and fire detection devices. Fire Journal. July, 86-91(+130).

[10] Kahn, M. J. (1984). Human awakening and subsequent identification of fire-related cues. Fire Technology, 20(1), 20-26. doi:10.1007/BF02390045

[11] Bruck, D. and Horasan, M. (1995). Non-arousal and non-action of normal sleepers in response to a smoke detector alarm. Fire Safety Journal, 25, 125-139. doi:10.1016/0379-7112(95)00041-0

[12] Bruck, D. (1999). Non-awakening in children in response to a smoke detector alarm. Fire Safety Journal, 32, 369-376. doi:10.1016/S0379-7112(98)00035-6

[13] Du Bois, .J, Ashley, E., Klassen, M. and Roby, R. (2005). Waking effectiveness of audible, visual and vibratory emergency alarms on people of all hearing abilities. Proceedings of the Accessible Emergency Notification and Communication: State of the Science Conference, Gallaudet University, Washington D.C. Nov 2-3, 2005.

[14] Bruck, D. and Bliss, R.A. (2000). Sleeping children and smoke alarms. Proceedings of the $4^{\text {th }}$ Asia-Oceania Symposium on Fire Science and Technology, Asia-Oceania Association for Fire and Technology, Tokyo, pp. 602-613.

[15] Bruck D, Reid S, Kouzma J and Ball M (2004). The effectiveness of different alarms in waking sleeping children. Proceedings of the Third Human Behaviour in Fire Conference, Belfast, 1-3 October. London: Interscience Communications, pp. 279-290.

[16] Smith, G. Splaingard, M., Hayes, J., Xiang, H. (2006). Comparison of a personalized parent voice smoke alarm with conventional residential tone smoke alarm for awakening children. Pediatrics, 118: 1623-1632. doi:10.1542/peds.2006-0125

[17] Bruck, D. and Thomas, I. (2008). Comparison of the effectiveness of different emergency notification signals in sleeping older adults. Fire Technology , 44(1), 15-38. doi: 10.107/S10694007-0017-5

[18] Bruck, D. and Thomas, I. (2006). Reducing fire deaths in older adults: Investigation of auditory arousal with different alarm signals in sleeping older adults. Report for the Fire Protection Research Foundation.

[19] Ball, M. and Bruck, D. (2004). The effect of alcohol upon response to fire alarm signals in sleeping young adults. In: Shields J. (Ed.). Proceedings of the Third Human Behaviour in Fire Conference, Belfast, 1-3 October. London: Interscience Communications, pp. 291-302.

[20] Bruck, D. and Thomas, I. (2007). Waking effectiveness of alarms (auditory, visual and tactile) for adults who are hard of hearing. Report for the Fire Protection Research Foundation.

[21] Runyan, C. W., S. I. Bangdiwala, et al. (1992). "Risk factors for fatal residential fires." The New England Journal of Medicine 327(12), 859-863. 
[22] Bruck, D., Thomas, I. and Ball, M. (2007). Waking effectiveness of alarms (auditory, visual and tactile) for the alcohol impaired. Report for the Fire Protection Research Foundation.

[23] Patterson, R.D. (1990). Auditory warning sounds in the work environment. Phil. Trans. R. Soc. Lond. B 327, 485-492. doi:10.1098/rstb.1990.0091

[24] Berkowitz, J.P. and Casali, S.P. (1990). Influence of age on the ability to hear telephone ringers of different spectral content. Proceedings of the Human Factors and Ergonomics $34^{\text {th }}$ Annual Meeting. Human Factors and Ergonomics Society, Santa Monica, CA. pp. 132-136.

[25] Hunt, R.M. (1970). Determination of an effective tone ringer signal. Preprint number 722 (M-5) from the $38^{\text {th }}$ Convention of the Audio Engineering Society. Audio Engineering Society. New York, NY.

[26] Cruickshanks, K.J., Wiley, T.L., Tweed, T.S., Klein, B.E.K., Klein, R., Mares-Perlman, J.A. and Nondahl, D.M. (1998). Prevalence of hearing loss in older adults in Beaver Dam, Wisconsin: the epidemiology of hearing loss study. Am J Epidemiol, 148(9), 878-886.

[27] Quirt, J.D. (1985). Sound transmission through building components. Building Science Insight '85 Noise Control in Buildings, Institute for Research in Construction, Research Council Canada. 